Supplement of

\title{
Organic molecular tracers in the atmospheric aerosols from Lumbini, Nepal, in the northern Indo-Gangetic Plain: influence of biomass burning
}

Xin Wan et al.

Correspondence to: Zhiyuan Cong (zhiyuancong@itpcas.ac.cn) and Shichang Kang (shichang.kang@lzb.ac.cn)

The copyright of individual parts of the supplement might differ from the CC BY 3.0 License. 
Table S1 Recovery ratios of target compounds and internal standards.

\begin{tabular}{lcc}
\hline Compounds & Addition $(\mathrm{ppb})(\mathrm{n}=6)$ & Recovery $(\%)$ \\
\hline Levoglucosan & 20 & $81.6 \pm 10.4$ \\
Mannosan & 20 & $80.7 \pm 11.7$ \\
Galactosan & 20 & $76.3 \pm 9.43$ \\
p-Hydroxybenzoic acid & 20 & $80.8 \pm 9.78$ \\
Vanillic acid & 20 & $79.4 \pm 11.5$ \\
Syringic acid & 20 & $78.6 \pm 14.2$ \\
Dehydroabietic acid & 20 & $85.4 \pm 13.4$ \\
Methyl- $\beta$-D-xylanopyranoside & 20 & $90.1 \pm 13.2$ \\
$D_{3}$-malic acid & 20 & $70.5 \pm 14.6$ \\
\hline
\end{tabular}




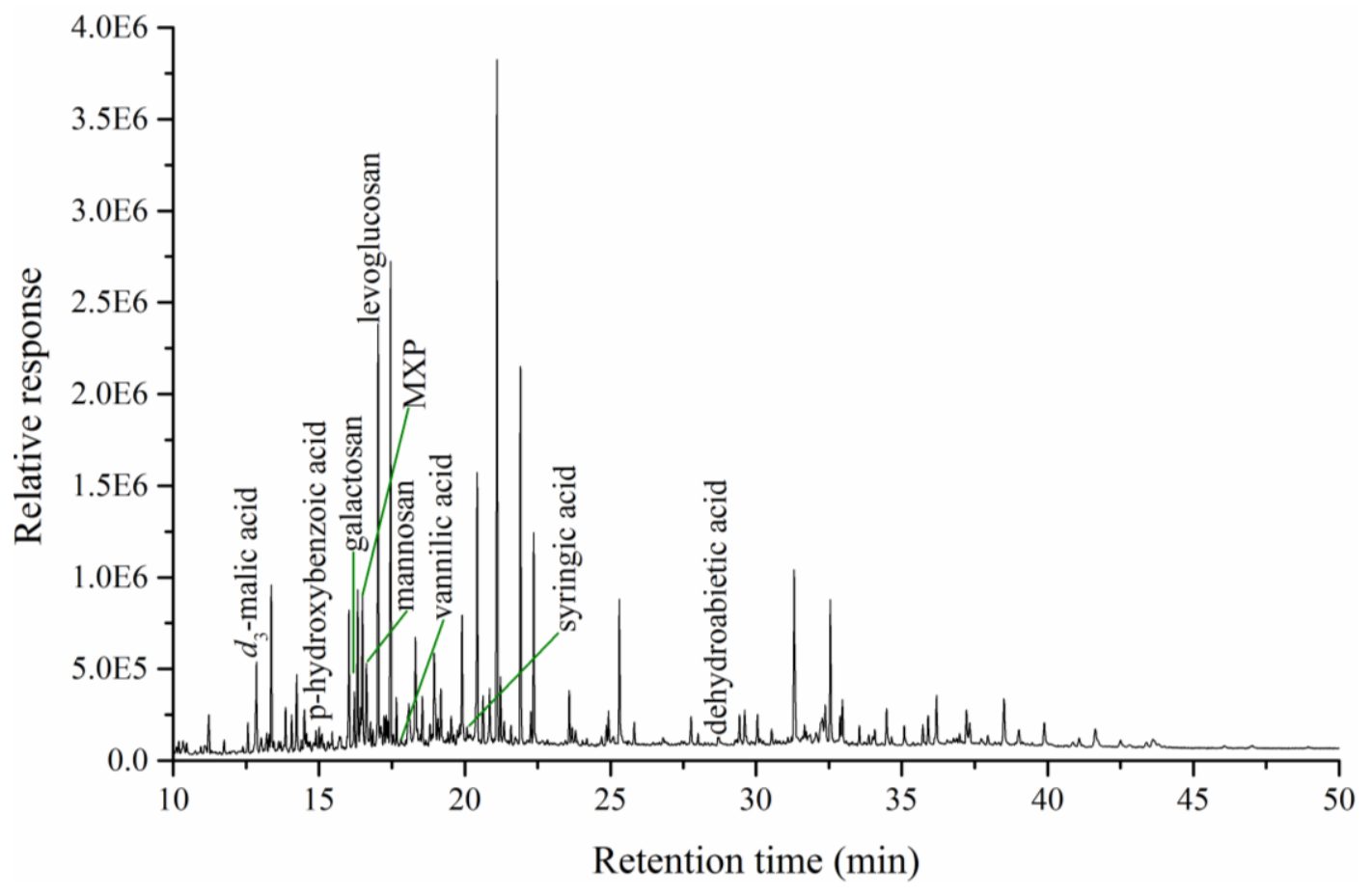

Fig. S1. Total ion chromatogram of organic tracers in a typical aerosol sample from Lumbini in southern Nepal. 


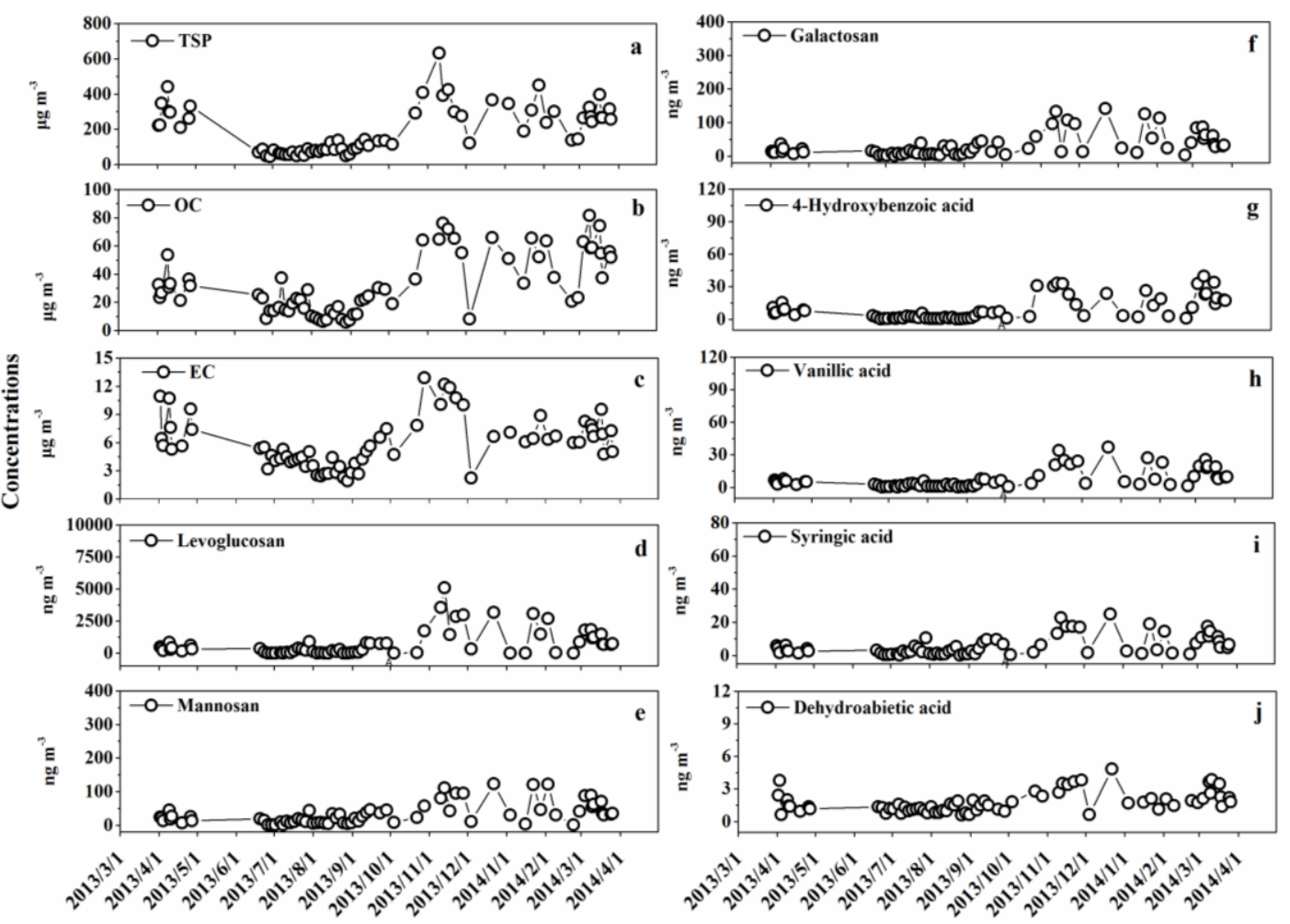

Fig. S2. Temporal variations in the concentrations of TSP, OC, EC, and organic tracers in Lumbini aerosols. 


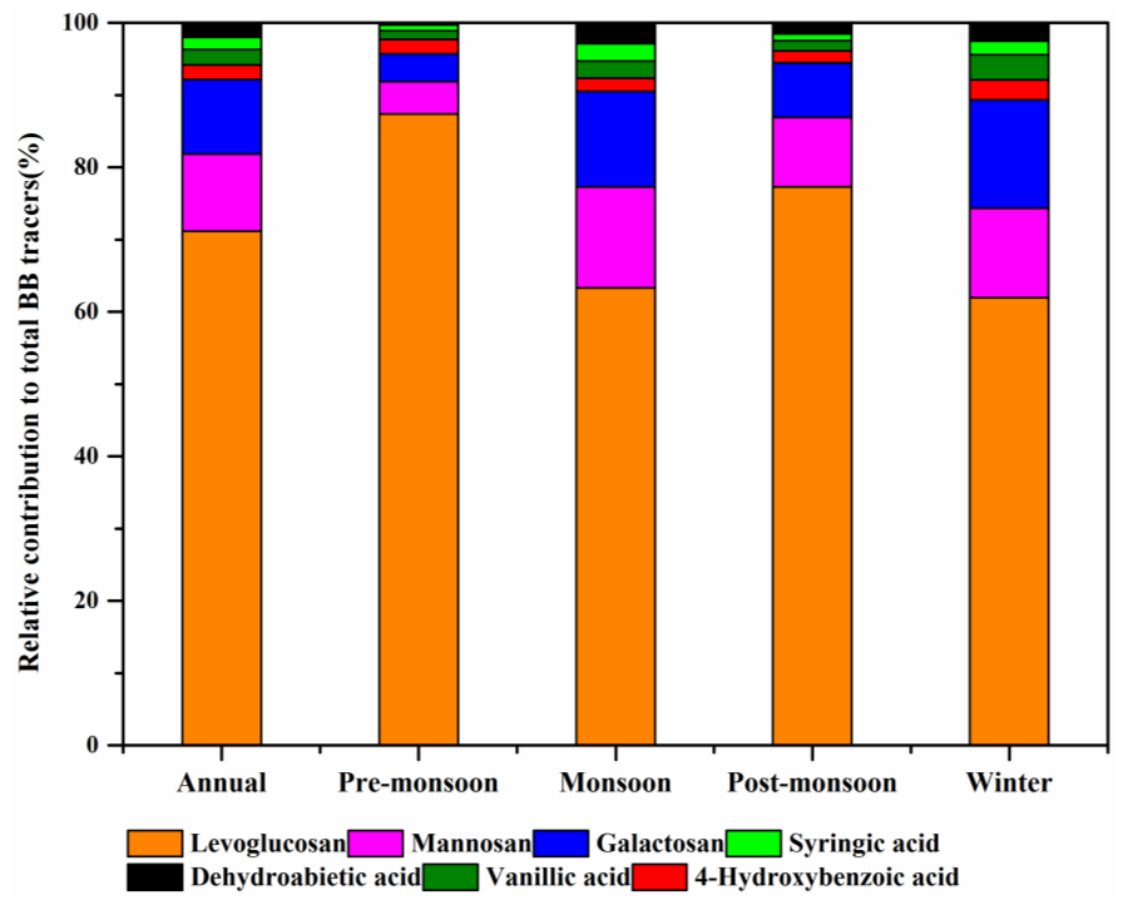

Fig. S3. Seasonal contributions of individual biomass burning tracers to total measured biomass burning tracers in TSP at Lumbini. 

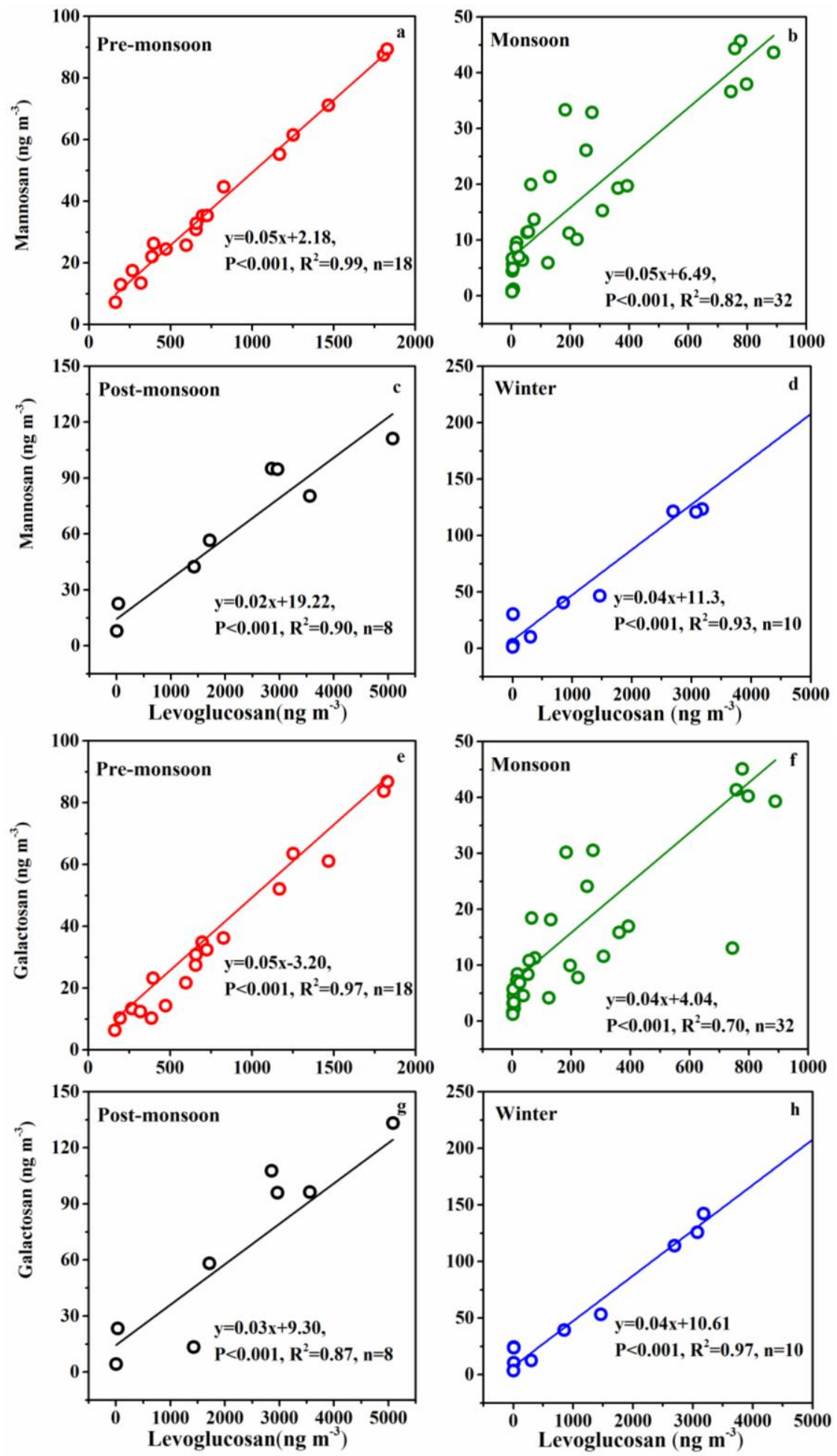

Fig. S4. Correlations between levoglucosan and mannosan, and levoglucosan and galactosan during different seasons. 

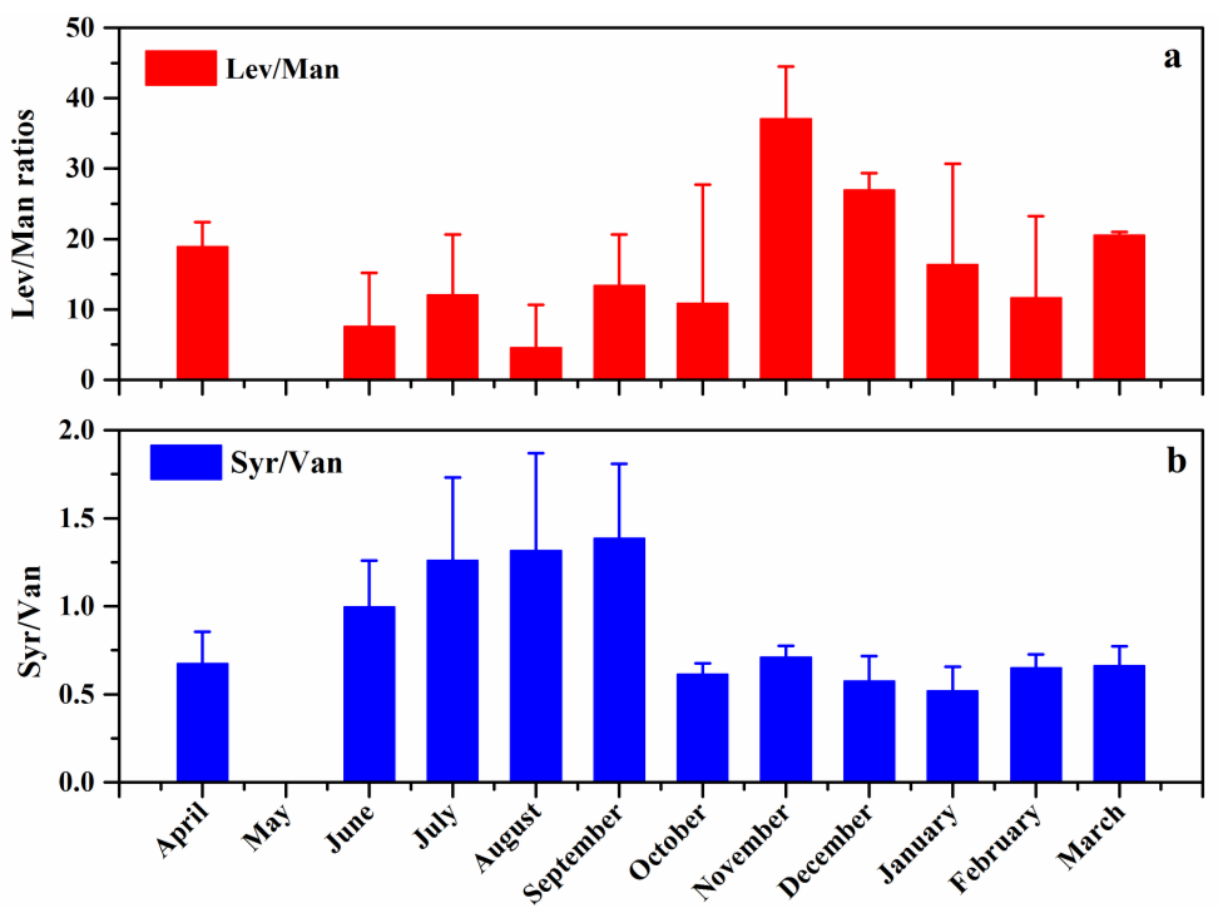

Fig. S5. Monthly variations of levoglucosan/mannosan (Lev/Man) and syringic acid/vanillic acid (Syr/Van) mass concentration ratios (The data of May, 2013 was missing due to the equipment breakdown). 

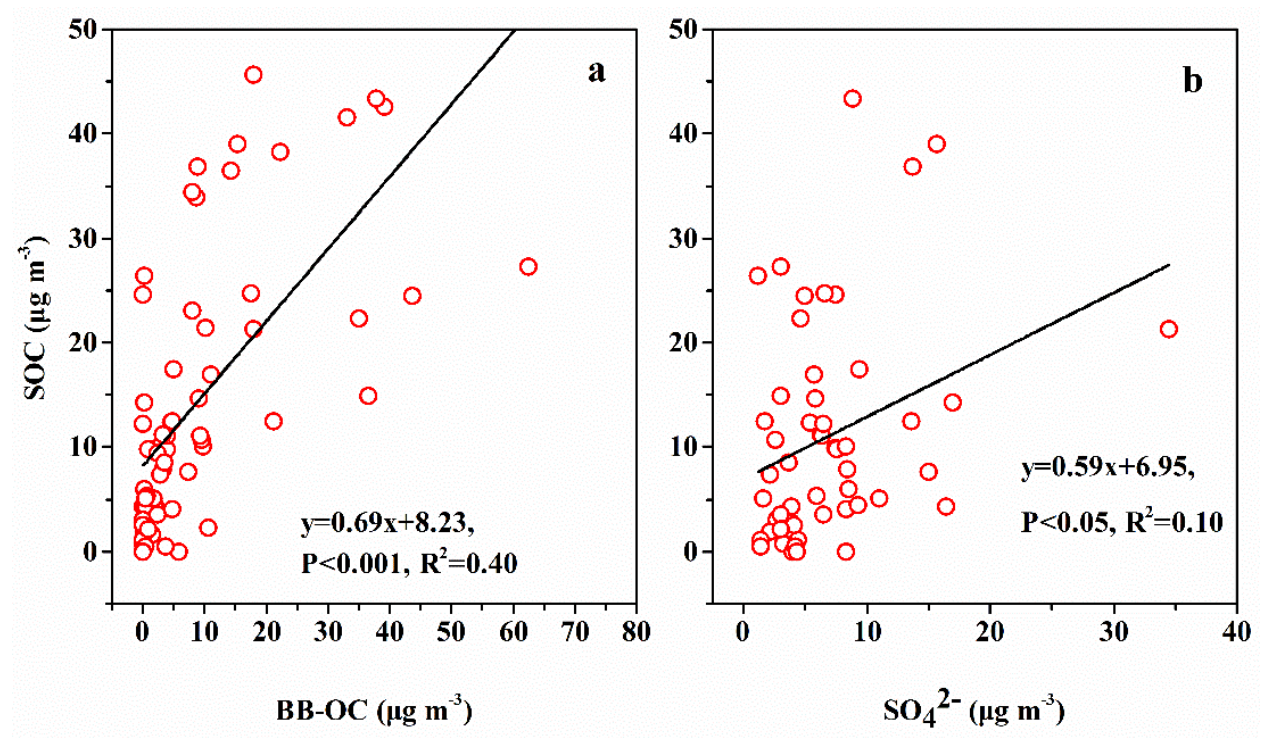

Fig. S6. Correlations between $\mathrm{SOC}$ and $\mathrm{BB}-\mathrm{OC}, \mathrm{SOC}$ and $\mathrm{SO}_{4}{ }^{2-}$ during different seasons in Lumbini aerosols. 